JASEM ISSN 1119-8362

All rights reserved
Full-text Available Online at www.bioline.org.br/ja
J. Appl. Sci. Environ. Manage. March, 2007

Vol. 11 (1) 91 - 100

\title{
A Risk Assessment Methodology for Toxic Chemicals Evaporation from Circular Pools
}

\author{
*SARAVANAN, R; KARUNANITHI,T; GOVINDARAJAN, L \\ ${ }^{I}$ Department of Chemical Engineering, Annamalai University, \\ Annamalainagar, India-608002 \\ ${ }^{2}$ Department of Mechanical and Industrial Engineering, \\ Caledonian College of Engineering, Sultanate of Oman
}

\begin{abstract}
This study presents a method for determining the mass transfer coefficient for the toxic chemicals evaporation from circular pools formed due to the failure of plant integrity or escape from valves. The approach used in this present research work is to develop a correlation by a robust optimization technique known as Genetic Algorithm from the experimental data. The developed correlation can be used to model the hydrocarbon evaporation from spills or releases at different wind speeds. From the mass transfer coefficient, the vapor concentration of the hydrocarbon spillage in the environment can be determined which can be used in quantitative risk analysis to predict the effect of toxic release. @JASEM
\end{abstract}

Emissions of hydrocarbons are one of the most serious hazards in chemical and petroleum industries. This occurs from various sources such as rupture of pipelines, valves and vessels in the highpressure operations. The scale of the possible fire, explosion and toxic release has grown and so has the area which might be affected by such events, especially outside the work boundary (Lees, 1991). Accidental releases of hazardous and toxic chemicals can cause a serious risk to a worker's safety and to the environment in Industries (Keun-Won Lee, 2002). An immediate concern is the generation of an excessive chemical vapor concentration downwind of the spill, which may cause health and fire hazards (Kawamura and Mackay, 1985). The objective of the present study is to develop a model for determining the mass transfer coefficient for the hydrocarbon evaporation from spills. Genetic algorithm has been applied to determine the model parameters at various wind speeds for the systems benzene, toluene, oxylene, carbon tetrachloride, acetone and ethyl acetate.

\section{MATERIALS AND METHODS}

Studies were made to determine the evaporation of benzene, toluene, o-xylene, carbon tetrachloride, acetone and ethyl acetate. The chemicals were supplied by Fischer and their purities were 99.5\%. Temperature was varied from 40 to $135^{\circ} \mathrm{C}$ depending on the boiling points of the systems and the wind speed varied from 1 to $3 \mathrm{~m} / \mathrm{s}$. Glass beaker of $0.087 \mathrm{~m}$ diameter was used as a container. Experiments were carried at different constant temperatures. The temperature was maintained with an accuracy of $\pm 0.5^{\circ} \mathrm{C}$. Wind conditions were simulated in the laboratory using an air circulator, which has provision for varying the speed. The velocity of air was measured using an anemometer. The rate of evaporation was determined for all the volatile liquids by measuring the decrease in level of the liquid in the container for a known period of time. Experiments were carried under different wind speed conditions. For different temperatures and wind speeds, evaporation rates were obtained from the slope of the straight lines from the plot of amount evaporated versus time for the said systems and the values are given in Tables 1 to 6.

Table 1 Comparison of Experimental and GA Predicted Values - Benzene

\begin{tabular}{cccccc}
\hline $\begin{array}{c}\text { Temperature } \\
(\mathrm{K})\end{array}$ & $\begin{array}{c}\text { Velocity } \\
(\mathrm{m} / \mathrm{s})\end{array}$ & $\begin{array}{c}\text { Evaporation } \\
\text { rate }(\mathrm{kg} / \mathrm{s})\end{array}$ & $\begin{array}{c}\mathrm{N}_{\mathrm{Sh}} \\
(\text { Experimental) }\end{array}$ & $\begin{array}{c}\mathrm{N}_{\mathrm{Sh}} \\
(\mathrm{GA})\end{array}$ & \% Error \\
\hline \multirow{3}{*}{323} & 1 & $4.00 \times 10^{-5}$ & 35.57 & 39.63 & 11.43 \\
& 1.5 & $7.20 \times 10^{-5}$ & 45.45 & 54.82 & 20.62 \\
& 2 & $9.00 \times 10^{-5}$ & 59.28 & 69.01 & 16.41 \\
& 2.5 & $1.05 \times 10^{-4}$ & 69.16 & 82.49 & 19.28 \\
& 3 & $1.40 \times 10^{-4}$ & 81.51 & 95.45 & 17.10 \\
\hline
\end{tabular}

\footnotetext{
*Corresponding author: E-mail: tsrsaravanan@yahoo.co.in

$\dagger$ On Leave from Annamalai University, India.
} 


\begin{tabular}{cccccc}
\hline & 1 & $1.14 \times 10^{-4}$ & 535.54 & 48.43 & -9.56 \\
333 & 1.5 & $1.33 \times 10^{-4}$ & 62.47 & 66.98 & 7.22 \\
& 2 & $1.60 \times 10^{-4}$ & 75.15 & 84.32 & 12.20 \\
& 2.5 & $2.11 \times 10^{-4}$ & 99.10 & 100.80 & 1.71 \\
& 3 & $2.46 \times 10^{-4}$ & 115.55 & 116.63 & 0.93 \\
\hline \multirow{3}{*}{343} & 1 & & & & \\
\hline & 1.5 & $2.05 \times 10^{-4}$ & 74.55 & 58.89 & -21.00 \\
& 2.5 & $2.50 \times 10^{-4}$ & 113.64 & 102.54 & -12.58 \\
& 3 & $3.07 \times 10^{-4}$ & 139.55 & 122.57 & -12.16 \\
& $3.42 \times 10^{-4}$ & 155.46 & 141.82 & -8.77 \\
\hline
\end{tabular}

Table 2 Comparison of Experimental and GA Predicted Values - Toluene

\begin{tabular}{cccccc}
\hline $\begin{array}{c}\text { Temperature } \\
(\mathrm{K})\end{array}$ & $\begin{array}{c}\text { Velocity } \\
(\mathrm{m} / \mathrm{s})\end{array}$ & $\begin{array}{c}\text { Evaporation } \\
\text { rate }(\mathrm{kg} / \mathrm{s})\end{array}$ & $\begin{array}{c}\mathrm{N}_{\text {Sh }} \\
(\text { Experimental })\end{array}$ & $\begin{array}{c}\mathrm{N}_{\text {Sh }} \\
(\mathrm{GA})\end{array}$ & \% Error \\
\hline \multirow{4}{*}{343} & 1 & $6.36 \times 10^{-5}$ & 29.40 & 33.53 & 14.02 \\
& 1.5 & $8.40 \times 10^{-5}$ & 39.20 & 46.37 & 18.29 \\
& 2 & $1.30 \times 10^{-4}$ & 60.67 & 58.37 & -3.79 \\
& 2.5 & $1.50 \times 10^{-4}$ & 70.01 & 69.78 & -0.32 \\
& 3 & $1.85 \times 10^{-4}$ & 86.34 & 80.74 & -6.49 \\
353 & 1 & $8.91 \times 10^{-5}$ & 38.55 & 40.03 & 3.83 \\
& 1.5 & $1.30 \times 10^{-4}$ & 56.25 & 55.37 & -1.56 \\
& 2 & $1.64 \times 10^{-4}$ & 70.96 & 69.70 & -1.78 \\
& 2.5 & $2.00 \times 10^{-4}$ & 86.53 & 83.32 & -3.72 \\
363 & 3 & $2.22 \times 10^{-4}$ & 90.61 & 96.40 & 6.39 \\
& 1 & $1.16 \times 10^{-4}$ & 47.45 & 40.03 & -15.63 \\
& 1.5 & $1.58 \times 10^{-4}$ & 71.58 & 55.37 & -14.33 \\
& 2 & $1.75 \times 10^{-4}$ & 98.17 & 69.70 & -2.63 \\
& 2.5 & $2.40 \times 10^{-4}$ & 106.76 & 83.32 & -15.13 \\
& 3 & $2.95 \times 10^{-4}$ & 148.07 & 96.40 & -20.11 \\
\hline \multirow{3}{*}{373} & 1 & $1.73 \times 10^{-4}$ & 68.14 & 56.30 & -17.37 \\
& 1.5 & $2.43 \times 10^{-4}$ & 94.23 & 77.87 & -17.35 \\
& 2 & $3.00 \times 10^{-4}$ & 116.81 & 98.03 & -16.08 \\
& 2.5 & $3.52 \times 10^{-4}$ & 136.28 & 117.19 & -14.01 \\
& 3 & $4.40 \times 10^{-4}$ & 171.32 & 135.59 & -20.86 \\
\hline
\end{tabular}

Table 3 Comparison of Experimental and GA Predicted Values - o-Xylene

\begin{tabular}{cccccc}
\hline $\begin{array}{c}\text { Temperature } \\
(\mathrm{K})\end{array}$ & $\begin{array}{c}\text { Velocity } \\
(\mathrm{m} / \mathrm{s})\end{array}$ & $\begin{array}{c}\text { Evaporation } \\
\text { rate }(\mathrm{kg} / \mathrm{s})\end{array}$ & $\begin{array}{c}\text { NSh } \\
(\text { Experimental })\end{array}$ & $\begin{array}{c}\text { NSh } \\
(\mathrm{GA})\end{array}$ & \% Error \\
\hline \multirow{3}{*}{378} & 1 & $9.44 \times 10-5$ & 36.28 & 33.51 & -7.65 \\
& 1.5 & $1.17 \times 10-4$ & 44.97 & 46.35 & 3.06 \\
& 2 & $1.53 \times 10-4$ & 58.80 & 58.34 & -0.79 \\
& 2.5 & $1.71 \times 10-4$ & 65.72 & 69.74 & 6.12 \\
& 3 & $2.22 \times 10-4$ & 85.32 & 80.69 & -5.43 \\
388 & 1 & $1.00 \times 10-4$ & 36.80 & 40.03 & 8.79 \\
& 1.5 & $1.40 \times 10-4$ & 51.51 & 55.37 & 7.48 \\
& 2 & $1.87 \times 10-4$ & 68.81 & 69.70 & 1.29 \\
398 & 2.5 & $2.25 \times 10-4$ & 82.79 & 83.32 & 0.64 \\
& 3 & $2.67 \times 10-4$ & 98.24 & 96.40 & -1.78 \\
\hline & 1 & $1.37 \times 10-4$ & 48.97 & 47.70 & -2.61 \\
& 1.5 & $2.00 \times 10-4$ & 71.49 & 65.97 & -7.72 \\
& 2 & $2.21 \times 10-4$ & 78.10 & 83.04 & 5.12 \\
& 2.5 & $3.17 \times 10-4$ & 113.31 & 99.27 & -12.39 \\
& 3 & $3.31 \times 10-4$ & 118.32 & 114.86 & -2.92 \\
\hline
\end{tabular}

Table 4 Comparison of Experimental and GA Predicted Values - Carbon tetrachloride

\begin{tabular}{cccccc}
\hline $\begin{array}{c}\text { Temperature } \\
(\mathrm{K})\end{array}$ & $\begin{array}{c}\text { Velocity } \\
(\mathrm{m} / \mathrm{s})\end{array}$ & $\begin{array}{c}\text { Evaporation } \\
\text { rate }(\mathrm{kg} / \mathrm{s})\end{array}$ & $\begin{array}{c}\mathrm{N}_{\text {Sh }} \\
(\text { Experimental })\end{array}$ & $\begin{array}{c}\mathrm{N}_{\mathrm{Sh}} \\
(\mathrm{GA})\end{array}$ & \% Error \\
\hline & 1 & $1.30 \times 10^{-4}$ & 61.10 & 68.49 & 11.19 \\
323 & 1.5 & $1.80 \times 10^{-4}$ & 85.29 & 94.73 & 11.07 \\
& 2 & $2.50 \times 10^{-4}$ & 118.46 & 119.25 & 0.67 \\
& 2.5 & $2.70 \times 10^{-4}$ & 127.93 & 142.56 & 11.43 \\
& 3 & $3.00 \times 10^{-4}$ & 142.15 & 164.94 & 16.03 \\
\hline
\end{tabular}




\begin{tabular}{cccccc}
\hline \multirow{3}{*}{333} & 1 & $1.90 \times 10^{-4}$ & 85.09 & 82.53 & -3.01 \\
& 1.5 & $2.50 \times 10^{-4}$ & 111.96 & 114.15 & 1.95 \\
& 2 & $2.70 \times 10^{-4}$ & 120.92 & 143.69 & 18.83 \\
& 2.5 & $3.70 \times 10^{-4}$ & 165.70 & 171.77 & 3.66 \\
343 & 3 & $4.10 \times 10^{-4}$ & 183.62 & 198.75 & 8.24 \\
\hline \multirow{3}{*}{3} & $2.30 \times 10^{-4}$ & 99.67 & 99.45 & -0.21 \\
& 1.5 & $3.60 \times 10^{-4}$ & 152.53 & 137.56 & -9.81 \\
& 2.5 & $4.30 \times 10^{-4}$ & 182.87 & 173.16 & -5.31 \\
& 3 & $5.20 \times 10^{-4}$ & 225.33 & 207.00 & -8.13 \\
& $5.50 \times 10^{-4}$ & 238.33 & 239.51 & 0.49 \\
\hline
\end{tabular}

Table 5 Comparison of Experimental and GA Predicted Values - Acetone

\begin{tabular}{cccccc}
\hline $\begin{array}{c}\text { Temperature } \\
(\mathrm{K})\end{array}$ & $\begin{array}{c}\text { Velocity } \\
(\mathrm{m} / \mathrm{s})\end{array}$ & $\begin{array}{c}\text { Evaporation } \\
\text { rate }(\mathrm{kg} / \mathrm{s})\end{array}$ & $\begin{array}{c}\mathrm{N}_{\text {Sh }} \\
(\text { Experimental })\end{array}$ & $\begin{array}{c}\mathrm{N}_{\text {Sh }} \\
(\mathrm{GA})\end{array}$ & \% Error \\
\hline \multirow{3}{*}{313} & 1 & $9.17 \times 10^{-5}$ & 50.64 & 48.80 & -3.64 \\
& 1.5 & $1.45 \times 10^{-4}$ & 80.08 & 67.49 & -15.71 \\
& 2 & $1.70 \times 10^{-4}$ & 93.88 & 84.96 & -9.50 \\
& 2.5 & $2.08 \times 10^{-4}$ & 114.87 & 101.57 & -11.58 \\
& 3 & $2.55 \times 10^{-4}$ & 140.84 & 117.51 & -16.55 \\
318 & 1 & $1.07 \times 10^{-4}$ & 56.72 & 53.50 & -5.67 \\
& 1.5 & $1.25 \times 10^{-4}$ & 66.26 & 74.00 & 11.69 \\
& 2 & $1.53 \times 10^{-4}$ & 76.33 & 93.15 & 14.86 \\
323 & 2.5 & $1.78 \times 10^{-4}$ & 94.35 & 111.36 & 18.02 \\
& 3 & $2.21 \times 10^{-4}$ & 106.01 & 128.85 & 9.99 \\
\hline \multirow{3}{*}{32} & 1.5 & $1.69 \times 10^{-4}$ & 72.23 & 58.97 & -18.36 \\
& 2.5 & $2.00 \times 10^{-4}$ & 87.19 & 81.56 & -6.46 \\
& 3 & $2.75 \times 10^{-4}$ & 103.19 & 102.67 & -0.50 \\
& $2.17 \times 10^{-4}$ & 163.55 & 122.73 & -13.49 \\
& & & & 142.01 & -13.17 \\
\hline
\end{tabular}

Table 6 Comparison of Experimental and GA Predicted Values - Ethyl acetate

\begin{tabular}{cccccc}
\hline $\begin{array}{c}\text { Temperatur } \\
\mathrm{e}(\mathrm{K})\end{array}$ & $\begin{array}{c}\text { Velocity } \\
(\mathrm{m} / \mathrm{s})\end{array}$ & $\begin{array}{c}\text { Evaporation } \\
\text { rate }(\mathrm{kg} / \mathrm{s})\end{array}$ & $\begin{array}{c}\mathrm{N}_{\mathrm{Sh}} \\
(\text { Experimental })\end{array}$ & $\begin{array}{c}\mathrm{N}_{\mathrm{Sh}} \\
(\mathrm{GA})\end{array}$ & \% Error \\
\hline \multirow{3}{*}{323} & 1 & $1.13 \times 10^{-4}$ & 42.01 & 36.60 & -12.88 \\
& 1.5 & $1.50 \times 10^{-4}$ & 55.76 & 50.62 & -9.22 \\
& 2 & $1.80 \times 10^{-4}$ & 66.91 & 63.72 & -4.78 \\
& 2.5 & $2.17 \times 10^{-4}$ & 81.04 & 76.17 & -6.01 \\
& 3 & $2.75 \times 10^{-4}$ & 100.74 & 88.13 & -12.52 \\
333 & 1 & $1.50 \times 10^{-4}$ & 53.24 & 45.43 & -14.68 \\
& 1.5 & $1.67 \times 10^{-4}$ & 59.28 & 62.84 & 5.99 \\
& 2 & $2.18 \times 10^{-4}$ & 77.38 & 79.10 & 2.21 \\
343 & 2.5 & $2.57 \times 10^{-4}$ & 91.58 & 94.55 & 3.25 \\
& 3 & $3.12 \times 10^{-4}$ & 110.39 & 109.40 & -0.90 \\
\hline \multirow{3}{*}{3} & 1 & $2.10 \times 10^{-4}$ & 70.75 & 55.14 & -22.07 \\
& 2 & $2.25 \times 10^{-4}$ & 75.13 & 76.27 & 1.51 \\
& 2.5 & $3.00 \times 10^{-4}$ & 103.77 & 96.00 & -7.48 \\
& 3 & $3.43 \times 10^{-4}$ & 115.56 & 114.77 & -0.69 \\
\hline
\end{tabular}

Model to estimate the mass transfer coefficient: Leinonen and Mackay (1975) predicted a model of evaporation based on the molar flux of an evaporative component $i$ from a hydrocarbon spill and is given by

$$
N_{i}=k_{m}\left(P_{i}-P\right) / R T
$$

Equation 1 can be modified in terms of the rate of evaporation and it may be written as

$$
E=M k_{m} A\left(P_{i}-P\right) / R T
$$

For many cases, $P_{i}$ is much greater than $P$, and the Equation 2 is reduced to

$$
E=M k_{m} A P_{i} / R T
$$

The rate of evaporation data were used to estimate the mass transfer coefficient

$$
k_{m}=(E / A)(R T / P M)
$$

The mass transfer coefficient values were used to correlate the mass transfer coefficient as a function 
of wind speed, pool size, density and viscosity by the equation

$$
\begin{aligned}
& N_{S h}=c\left(N_{\mathrm{Re}}\right)^{x}\left(N_{S c}\right)^{y} \\
& \text { Where } N_{S h}=k_{m} d / D \quad(6) \\
& N_{\mathrm{Re}}=d v \rho / \mu \\
& N_{S c}=\mu / \rho D
\end{aligned}
$$

The mass transfer coefficient was calculated from the experimental data using the equation (4). The Wilke-Lee modification of the Hirschfelder-BirdSpotz (Treybal, 1981) method was used in establishing the diffusivity and the viscosity values were obtained from the Nomograph (Perry et al., 1984) of the viscosities of gases.

Genetic Algorithm: Genetic algorithms are a part of evolutionary computational algorithms, which is a rapidly growing area of artificial intelligence. Genetic algorithms are inspired by Darwin's theory of evolution. GA is a search technique based on the mechanics of natural selection and natural genetics. It combines solution evaluation with randomized, structured exchange of information between the solutions to obtain optimality. GA is a robust approach as there is no restriction on the solution space during the search. The optimum solution is searched by randomized information exchange, thereby simulating the survival of the fittest criterion of the Darwinian evolution among the chromosome structures. In every generation, a new set of artificial chromosomes is created using bits and pieces of the fittest of the old ones.

GA operates on several solutions simultaneously, gathering information from current search points and using it to direct subsequent searches, which makes GA less susceptible to land at local optimum values. GA offers significant savings in computational effort by selectively searching a much smaller fraction of the solution space for problems involving large number of discrete variables. It efficiently exploits historical information to speculate on new search points with expected improved performance. GA involves an intelligent way to search for the optimum solution to a problem hidden in a wealth of poorer ones (Govindarajan, 2004).

Estimation of Model Parameters Using Genetic Algorithm: In this research work GA, being a robust optimization technique, has been employed to determine the model parameters used to determine the mass transfer coefficient of hydrocarbon evaporation from spills under different wind speed conditions. The objective function value is the absolute difference between the simulated outputs resulting from using parameter set in model and the observed data. For example, a model can produce values for a single output, $y_{\text {model }}$ that can be compared against measured data for the same variable, $y_{\text {data }}$. An optimization technique attempts to find a set of parameter values minimizing an objective function, which is defined as the difference between $\mathrm{y}_{\text {model }}$ and $\mathrm{y}_{\text {data }}$. There are considerable technical issues in optimization, particularly ensuring a global minimum. Hence the use of genetic algorithm, a global optimization technique is justified for the estimation of model parameters used to determine the mass transfer coefficient of hydrocarbon evaporation.

The objective function is defined as

$\min \Psi=\sum_{\mathrm{i}}^{\mathrm{N}}\left|\mathrm{y}_{\text {mod el }}-\mathrm{y}_{\exp }\right|$

where $\mathrm{i}=1,2, \ldots \ldots, \mathrm{N}$ are the experimental data points.

subject to

$0<c<1$

$0<x<1$

$0<y<1$

The limit values of model parameters can be set at any positive values of wider range. Hence GA based methodology is also efficient in finding the suitability of a model given the experimental values. If the experimental value does not fit for a reasonable value of model parameters, it indicates the assumed model is not suitable for the system considered under the conditions of experiments. A penalty function approach is used to handle the limitviolated constraints. Hence the objective function is given by

$$
\begin{aligned}
& \operatorname{Min} \psi=\sum_{\mathrm{i}}^{\mathrm{N}}\left|\mathrm{y}_{\text {mod el }}-\mathrm{y}_{\exp }\right|+ \\
& \lambda\left[\sum_{\mathrm{z} \in \mathrm{LVC}}^{\mathrm{N}}\left|\mathrm{C}_{\mathrm{z}}-\mathrm{C}_{\mathrm{z} \text { (limit) }}\right|\right]
\end{aligned}
$$

The fitness is obtained by transforming the minimization problem into a maximization problem as

$$
\mathrm{FIT}=\frac{1}{1+\psi}
$$

\section{RESULTS AND DISCUSSION}

The evaporation rate is plotted against temperature for different wind speed conditions which is shown in the figures 1 to 6 . It is evident from the plots that temperature increases linearly with rate of evaporation in most of the cases. The experimental and GA predicted values of $N_{S h}$ were compared and are presented in Figures 1 to 12 for the 
systems benzene, toluene, o-xylene, carbon tetrachloride, acetone and ethyl acetate respectively.

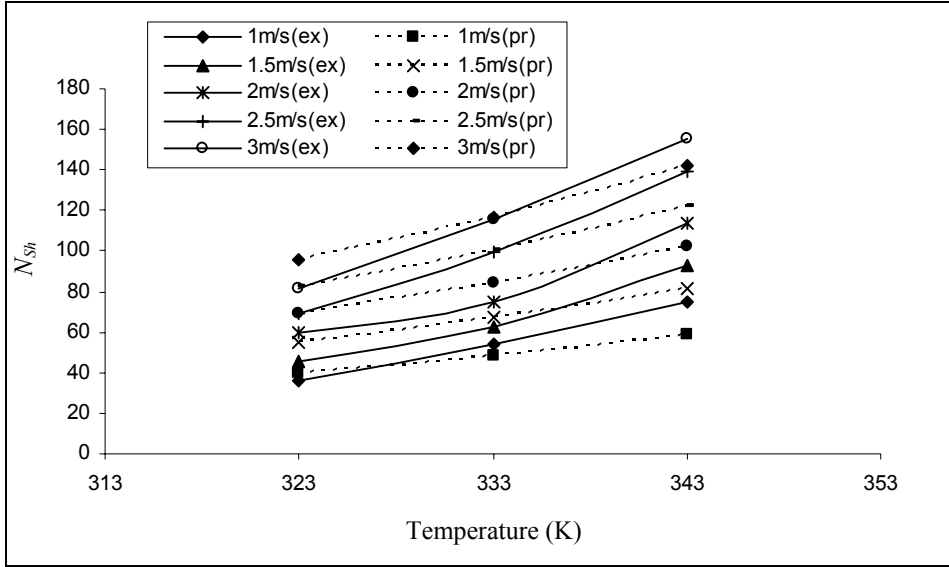

Fig. $1 N_{S h}$ Vs Temperature - Benzene

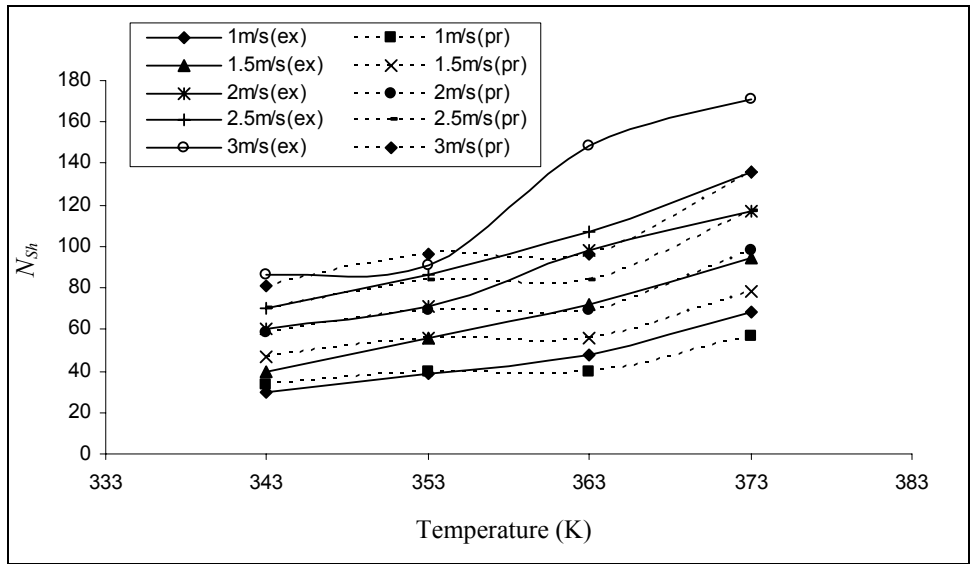

Fig.2 $N_{S h}$ Vs Temperature - Toluene

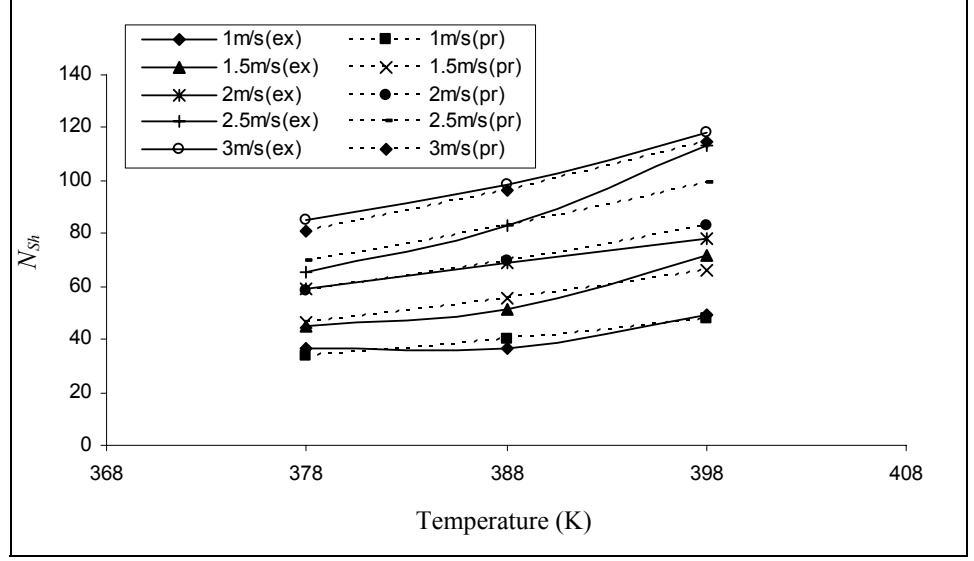

Fig.3 $N_{S h}$ Vs Temperature - o-Xylene 


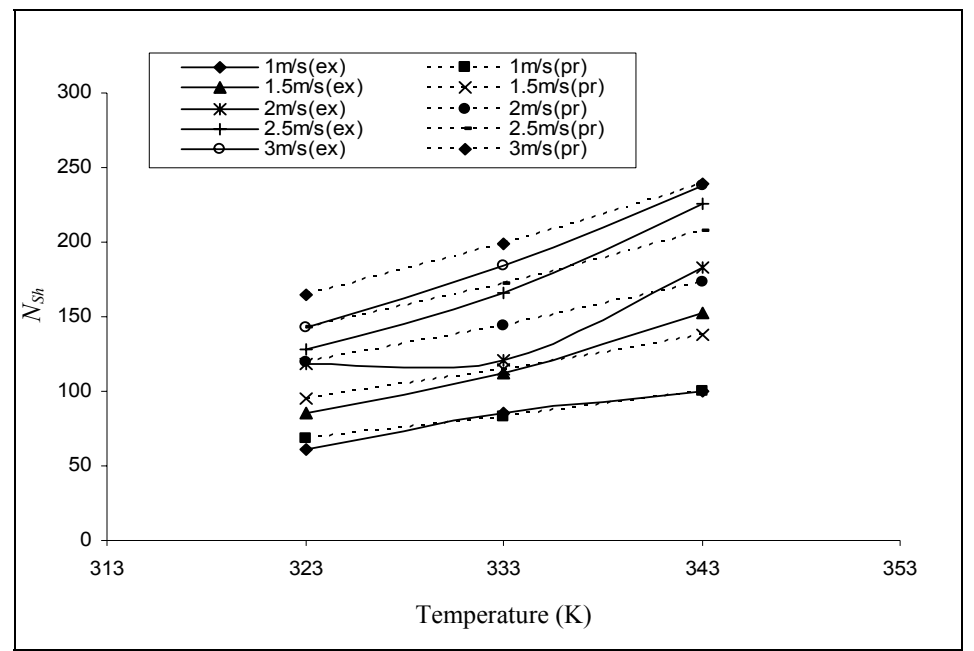

From the figures, it is understood that the predictions are acceptable with lesser percentage of error at intermediate temperatures. Also, it should be noted that the predicted values are less than the experimental values when the system is close to its boiling conditions. The GA predicted model parameters are given in Table 7. From the GA predicted model parameter values, the equation (5) can be rewritten as

$$
N_{S h}=0.06\left(N_{\mathrm{Re}}\right)^{0.80}\left(N_{S c}\right)^{0.70}
$$

Table 7 GA Predicted Model Parameters for Hydrocarbon Evaporation from Spills

\begin{tabular}{cc}
\hline Parameters & GA Values \\
$c$ & 0.06 \\
$x$ & 0.80 \\
$y$ & 0.70 \\
\hline
\end{tabular}

From the above relationship, the Sherwood number can be evaluated provided the natures of hydrocarbon and pool diameters are known. The mass transfer coefficient can be calculated from the Sherwood number by the equation (14) which can be used to model the hydrocarbon spill and in the development of simulation software to mitigate the hazardous situations.

Fig.4 $N_{S h}$ Vs Temperature $-\mathrm{CCl}_{4}$

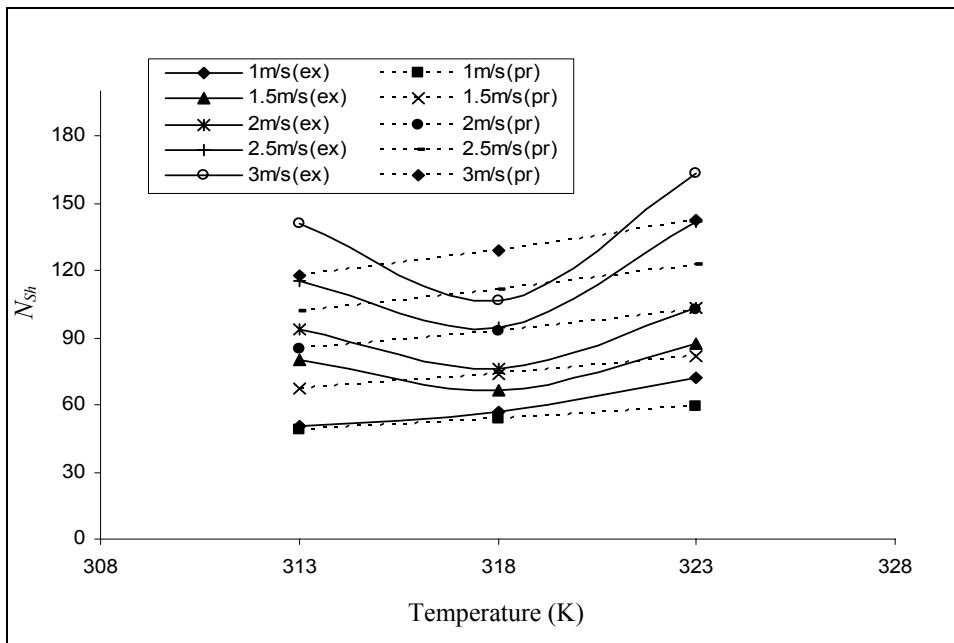

Fig.5 $N_{S h}$ Vs Temperature - Acetone 


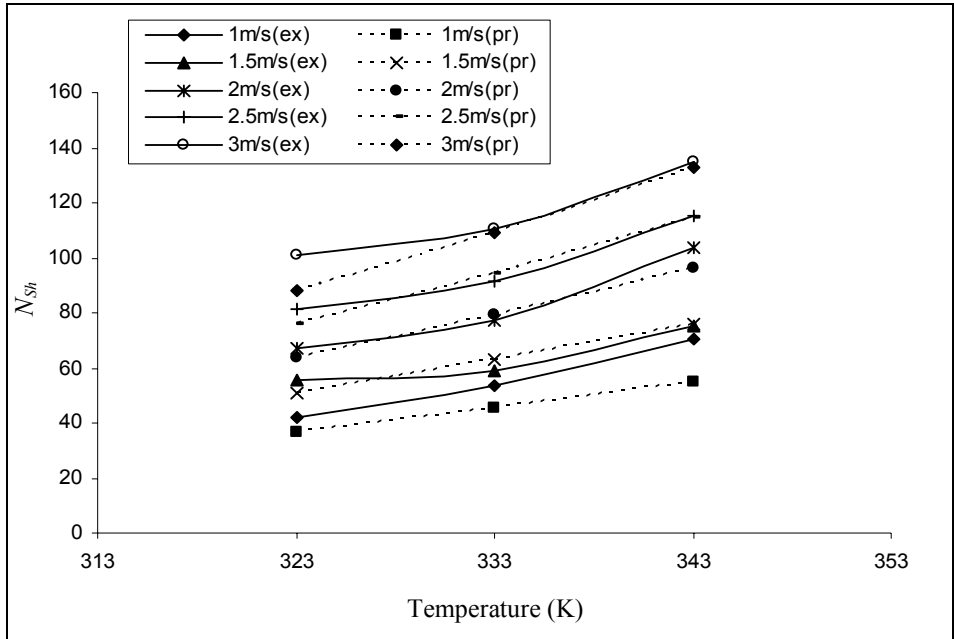

Fig.6 $N_{S h}$ Vs Temperature - Ethyl Acetate

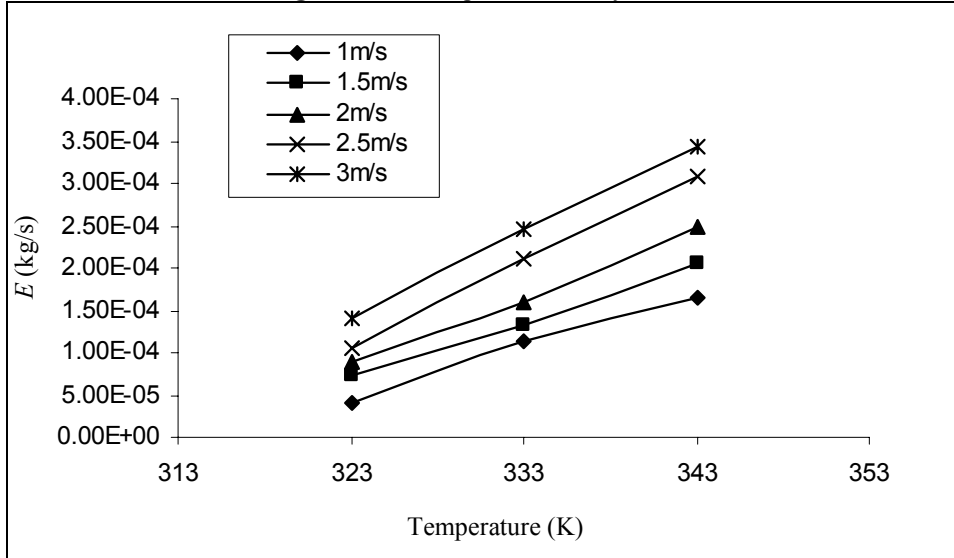

Fig.7 Evaporation rate Vs Temperature - Benzene

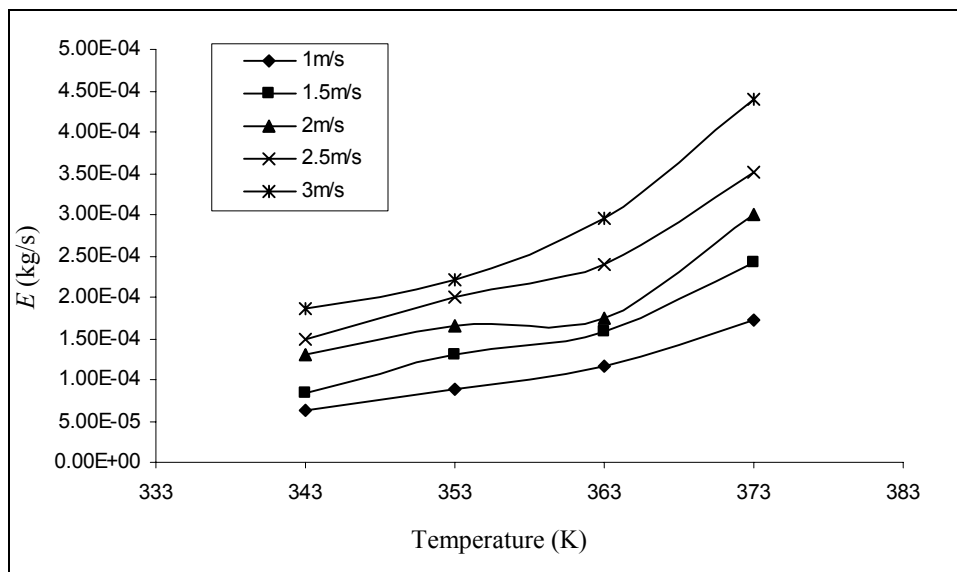

Fig.8 Evaporation rate Vs Temperature - Toluene 


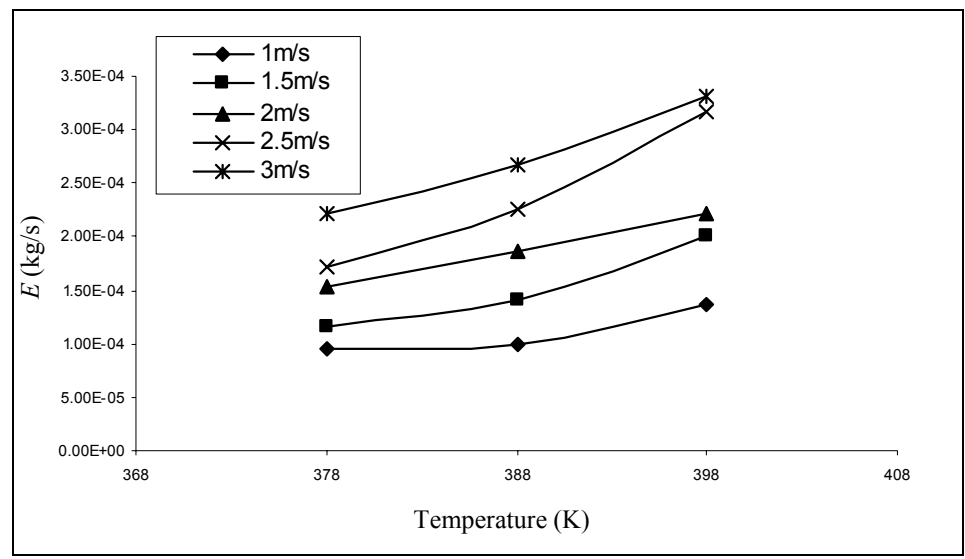

Fig.9 Evaporation rate Vs Temperature - o-Xylene

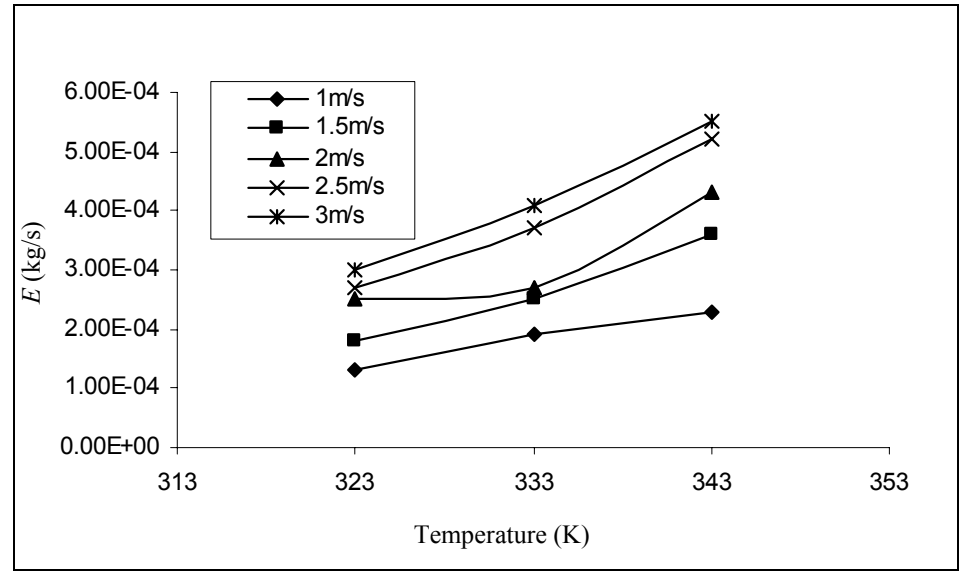

Fig.10 Evaporation rate Vs Temperature $-\mathrm{CCl}_{4}$

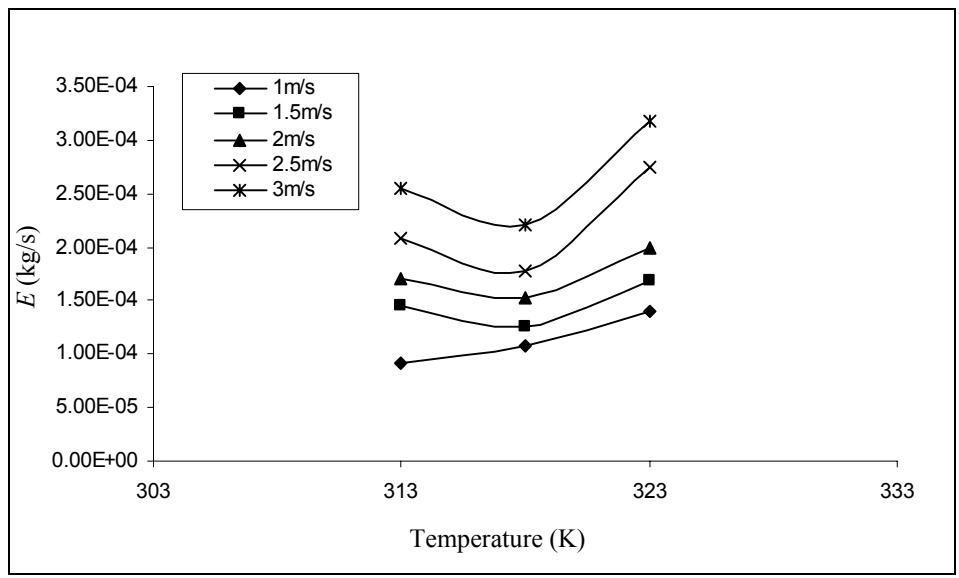

Fig.11 Evaporation rate Vs Temperature - Acetone 


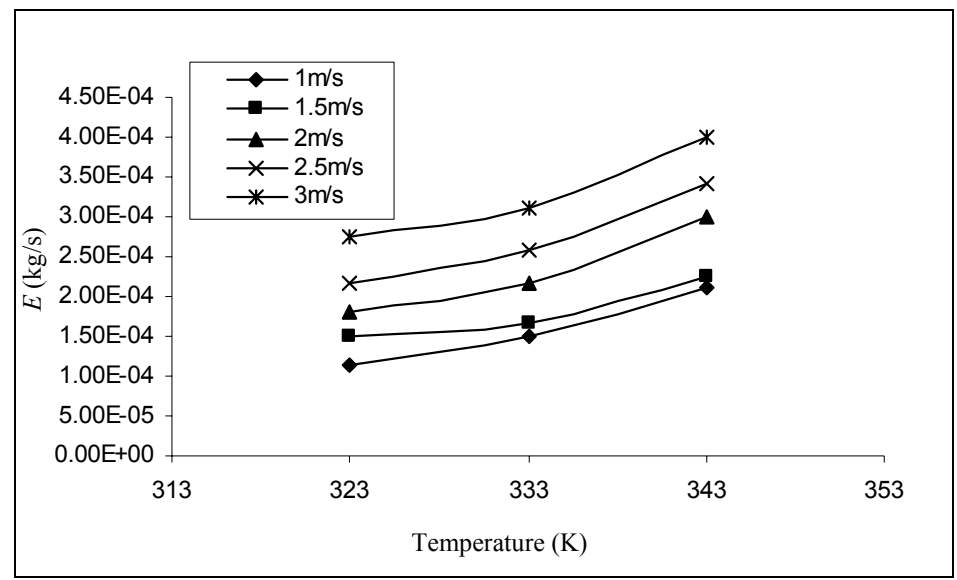

Fig.12 Evaporation rate Vs Temperature - Ethyl Acetate

$k_{m}=\frac{D}{d} \times N_{S h}$

Conclusion: Experiments were carried out in laboratory for the evaporation of benzene, toluene, oxylene, carbon tetrachloride, acetone and ethyl acetate at different wind speeds to model the hydrocarbon evaporation. Based on the results, a correlation is developed for the determination of mass transfer coefficient. The present study assumes the significance of the mass transfer coefficient value which is needed to determine the vapor concentration of the hydrocarbon spillage in the environment, that can be used in quantitative risk analysis to predict the effect of toxic release. Genetic algorithm has been found to be successful in determining the model parameters for wide range of experimental conditions. Hence GA based optimization methodology can also be efficiently used to predict the model parameters from the experimental data in the field of environmental and safety engineering.

Acknowledgement: The authors are indebted to the authorities of the Annamalai University, Annamalainagar, India and wish to express their gratitude for the support extended by them in carrying out this research work.

\section{REFERENCES}

Frank P. Lees, (1991). Loss Prevention in the Process Industries, Vol. 1, Butterworth-Heinemann, Oxford.

Govindarajan, L; Karunanithi, T (2004). Design Optimization of Process Plants Using Real Coded Genetic Algorithm, Chemical and Biochemical Engineering Quarterly, 18, 353.

Kawamura and Mackay, (1987). The evaporation of volatile liquids, Journal of Hazardous Materials, 15, 343364

Keun-Won Lee,(2002). A methodology for assessing risk from released hydrocarbon in an enclosed area, Journal of Loss Prevention in the process Industries, $15,11-17$.

Leinonen, P J; Mackay, D (1975). A mathematical model of evaporation and discussion from oil spills on ice, land water and under ice. In proceedings of the Tenth Canadian Symposium, water pollution research, Canada, 132 - 141.

Robert E. Treybal (1981). Mass-Transfer operations, Mc Graw Hill, Singapore.

Robert H. Perry; Don Green (1984). Chemical Engineers' Handbook, Mc Graw Hill, Singapore.

Robert C. Reid; John M. Prausnitz; Bruce E. Poling (1988). The Properties of Gases and Liquids, Mc Graw Hill, Singapore

\section{NOMENCLATURE}

A Area of evaporation $\left(\mathrm{m}^{2}\right)$

c Constant

$d \quad$ Diameter of the pool (m)

$D \quad$ Diffusivity $\left(\mathrm{m}^{2} / \mathrm{s}\right)$ 


$\begin{array}{ll}E & \text { Rate of evaporation }(\mathrm{kg} / \mathrm{s}) \\ k_{m} & \text { Mass transfer coefficient }(\mathrm{m} / \mathrm{s}) \\ M & \text { Molecular weight }(\mathrm{kg} / \mathrm{kg}-\mathrm{mol}) \\ N_{i} & \text { Evaporative molar flux of i }\left(\mathrm{mol} / \mathrm{m}^{2} \mathrm{~s}\right) \\ N_{R e} & \text { Reynolds number } \\ N_{s c} & \text { Schmidt number } \\ N_{s h} & \text { Sherwood number } \\ P_{i} & \text { Vapor pressure of component i }\left(\mathrm{N} / \mathrm{m}^{2}\right) \\ P & \text { Partial pressure of hydrocarbon }\left(\mathrm{N} / \mathrm{m}^{2}\right) \\ R & \text { Universal gas constant }(8314 \mathrm{~N} \mathrm{~m} / \mathrm{kmol} \mathrm{K}) \\ T & \text { Temperature }(\mathrm{K}) \\ & \text { Density }\left(\mathrm{kg} / \mathrm{m}^{3}\right) \\ & \text { Viscosity }\left(\mathrm{N} \mathrm{s} / \mathrm{m}^{2}\right) \\ v & \text { Wind speed }(\mathrm{m} / \mathrm{s}) \\ x & \text { Constant } \\ y & \text { Constant }\end{array}$

